\title{
Signs of Degeneration in 12-22-Year Old Grafts of Mesencephalic Dopamine Neurons in Patients with Parkinson's Disease
}

\author{
Zuzanna Kurowska $^{\mathrm{a}, \mathrm{b}}$, Elisabet Englund ${ }^{\mathrm{c}}$, Håkan Widner ${ }^{\mathrm{d}}$, Olle Lindvalle ${ }^{\mathrm{e}, 1}$ and Jia-Yi Li ${ }^{\mathrm{a}, \mathrm{b}, *, 1}$ \\ and Patrik Brundin ${ }^{\mathrm{a}, 1}$ \\ ${ }^{a}$ Neuronal Survival Unit, Wallenberg Neuroscience Center, Lund, Sweden \\ ${ }^{\mathrm{b}}$ Neural Plasticity and Repair Unit, Wallenberg Neuroscience Center, Lund, Sweden \\ ${ }^{\mathrm{c}}$ Department of Neuropathology, University Hospital, Lund University, Lund, Sweden \\ ${ }^{\mathrm{d}}$ Division of Neurology, Department of Clinical Sciences, Lund University, Lund, Sweden \\ ${ }^{\mathrm{e}}$ Laboratory of Neurogenesis and Cell Therapy, Wallenberg Neuroscience Center, University Hospital, \\ Lund, Sweden
}

\begin{abstract}
We demonstrate that grafted human fetal mesencephalic neurons can survive and extend axons for 22 years in the brain of a patient with Parkinson's disease (PD). In this patient, the overall survival and fiber outgrowth of the grafts were, however, relatively poor, which is consistent with the lack of significant clinical graft-induced benefit. We have compared the morphology of neurons in the 22-year old grafts with those in two younger grafts (16- and 12-year old), which were sequentially implanted in another PD patient. In the case with the 22-year-old transplant, a high proportion (up to 38\%) of the grafted dopaminergic (pigment-granule containing) neurons do not express tyrosine hydroxylase and dopamine transporter and their perikarya appear atrophic. The proportion of pigmented neurons not expressing these markers is lower in the 12-16 year old grafts. Furthermore, in the 22-year-old graft, $49 \%$ of the pigmented neurons display $\alpha$-synuclein immunoreactivity in the cell body and $1.2 \%$ of them contain Lewy bodies. In conclusion, our results show that grafted dopaminergic neurons can survive for more than two decades. However, over time an increasing proportion of grafted neurons exhibit signs of degeneration.
\end{abstract}

Keywords: Neural, transplantation, graft survival, dopamine, phenotype, tyrosine hydroxylase, alpha-synuclein, Lewy bodies

\section{INTRODUCTION}

Grafted human fetal dopaminergic neurons can survive, extend axons, release dopamine and functionally integrate in the striatum of patients with Parkinson's disease (PD) [1]. The reported functional outcome has varied greatly between patients, ranging from major improvement, allowing some patients to withdraw L-dopa medication for more than a decade, to

\footnotetext{
${ }^{1}$ Senior authors.

*Correspondence to: Dr. Jia-Yi Li, Neural Plasticity and Repair Unit, Wallenberg Neuroscience Center, Lund University, BMC A10, 22184 Lund, Sweden. Tel.: +46 46 2220525; Fax: +46 462220531; E-mail: jia-yi.li@med.lu.se.
}

no functional benefit in other cases. Based on positron emission tomography studies, these differences in outcome appear to be partly explicable by differences in graft survival and function at the neurochemical level [2], and partly by the extent of dopaminergic denervation in brain areas not reached by the grafts [3]. Detailed morphological analyses of post-mortem samples might shed more light on why some grafts function well while others do not.

Post-mortem studies have shown two abnormalities occur in neurons grafted to subjects with PD, namely down-regulation of tyrosine hydroxylase (TH) and dopamine transporter (DAT) [4-6] normally expressed in dopaminergic neurons, and abnormal han- 
dling of $\alpha$-synuclein. Kordower and coworkers have reported reduced DAT expression in dopaminergic neurons already 4 years after transplantation, whereas decreased TH expression was apparent after 14 years [4]. $\alpha$-Synuclein gradually accumulates in grafted dopaminergic neurons several years after surgery [5, 7] and eventually contributes to the formation of Lewy bodies (LBs) and Lewy neurites [4-8]. The LBs appear in a subpopulation (2-8\%) of grafted dopaminergic neurons and they also stain for several other LB markers (i.e., phosphorylated $\alpha$-synuclein, ubiquitin, Thioflavine-S) [5-9]. The generation of LBs in grafted neurons has been suggested to take place in two steps. First, soluble $\alpha$-synuclein slowly accumulates in the cytoplasm of neurons, including dopaminergic neurons. Second, $\alpha$-synuclein aggregates in an insoluble form, possibly triggered by a "seed" of misfolded $\alpha$ synuclein that is transmitted from host cells to the grafted neurons [10-14].

Here we have compared post-mortem brain specimens from two transplanted patients, called 'patient 1 ' and 'patient 3' according to grafting. Patient 1, who died at age of 69 , was grafted unilaterally in the putamen 22 years prior to death. She never exhibited any significant clinical benefit [15] probably due to poor graft survival caused by suboptimal surgical technique $[15,16]$. Patient 3 was implanted bilaterally 12 and 16 years before death, which occurred at an age of 65 . Clinically, he improved substantially for several years, which has been reported in earlier papers [7, 8, 16-20].

We had four objectives in the present study. First, to determine if dopaminergic neurons can survive and remain integrated in the Parkinsonian brain up to 22 years. Second, to examine whether the degree of graft survival and integration is associated with the widely different functional outcomes in our two patients. Third, to analyze whether the dopaminergic neurons contain Lewy bodies in the 22 year-old grafts and if the occurrence of Lewy bodies increases between 16 and 22 years after transplantation. Fourth, to monitor whether the dopaminergic phenotype of the grafted neurons, in terms of TH and DAT expression, is more compromised at 22 years after grafting than at 12 and 16 years.

\section{MATERIALS AND METHODS}

\section{Patient history}

\section{Patient 1}

This female patient was aged 47 years and had 14 years history of PD when she in 1987 received trans- plants of human fetal ventral mesencephalon (fresh tissue, cell suspension with small aggregates) unilaterally into left putamen ( 2 injection tracts) and left caudate nucleus (one injection tract). The grafting procedure, donor tissue, neurological outcome and imaging data have all been reported previously [15]. Briefly, Patient 1 experienced only very slight symptomatic relief during the first 6 months post-surgery and positron emission tomography showed no significant changes of fluorodopa uptake. At 3 years after grafting, she received subcutaneous infusion with apomorphine, and 8 years later deep brain stimulation was started bilaterally in the subthalamic nuclei with lasting beneficial effects. At 32-34 years after PD onset, she developed, diabetes, dysautonomia and subcortical dementia. In 2009, she had a large stroke of the right middle cerebral artery territory and died of acute bronchopneumonia 4 months later.

Routine neuropathologic analysis in patient 1 revealed signs of old ischemic-hypoxic damage in several areas in the right hemisphere following an ischemic insult 4 months prior to death.

\section{Patient 3}

This male patient was transplanted bilaterally 16 and 12 years before his death. His clinical course and history have been described in detail $[16,17,19,20]$. Briefly, in 1989, at age of 49, and 12 years after disease onset, the patient received grafts at 3 tracts into the left putamen. This intervention resulted in reduced time in off-phase, a longer duration of L-DOPA effect and a bilateral reduction of rigidity and hypokinesia in the off phase. Two years after grafting, his parkinsonian symptoms worsened on the side ipsilateral to the graft with increased rigidity and hypokinesia, whereas he continued to be improved on the contralateral side. Four years after the first transplantation, he received grafts at 5 tracts in the right putamen. This resulted in longer periods spent in the on phase and improved function in the left arm. Off-phase rigidity disappeared and timed motor tasks improved slightly contralateral to the second graft. However, after 13 months, the patient started to experience right-sided, painful off-phase related dystonia, which was L-dopa responsive. Due to multiple degenerated cervical disks, he developed a radiculopathy affecting the right hand and arm 22 months after transplantation. Regular assessments were stopped at 24 months after the second transplant. 


\section{Postmortem tissue preparation}

Brains were fixed in $6 \%$ buffered formaldehyde solution for about two months, followed by standard immunohistochemistry for paraffin embedded or frozen sections, as previously described [7, 8]. Forty micrometer thick free floating sections were cut and stained with antibodies against $\alpha$-synuclein, TH, DAT, G-protein regulated inward-rectifier potassium channel (Girk2), calbindin, ionized calcium binding adaptor molecule 1 (IBA-1), and glial fibrillary acidic protein (GFAP) [7, 8]. In addition to processing the graft regions, the brains were sectioned and processed for regular analysis of PD and other pathologies.

\section{Immunohistochemistry}

We stained sections from Patient 1 and 3 , as well as one age-matched subject without brain disease. Antigen retrieval was performed in $10 \mathrm{mM}$ sodium citrate $\mathrm{pH} 7.6,80^{\circ} \mathrm{C}, 30 \mathrm{~min}$ followed by incubation with quenching solution $\left(3 \% \mathrm{H}_{2} \mathrm{O}_{2}, 10 \%\right.$ methanol) for 15 min to block activity of endogenous peroxidase. Then we washed and blocked tissues for $1 \mathrm{~h}$ with $5 \%$ of adequate serum. We incubated sections with primary antibodies over-night (TH - Pel-Freez P40101-0 $1: 1000, \alpha$-synuclein - Zymed LB509 $1: 1000$, DAT Chemicon AB1766 1:500, IBA-1 Wako 019-19741 1:500, phosphorylated S129 $\alpha$-synuclein Abcam AB51253 1:1000, GFAP - Dako 20334 1:500). After washing, we applied biotin-conjugated secondary antibody ( $1: 200$, Vector Laboratories) for $1 \mathrm{~h}$, followed by washing and $1 \mathrm{~h}$ incubation with $\mathrm{ABC}$ solution (PK-6100, Vector Laboratories), washing and incubation with DAB-solution (SK-4100, Vector Laboratories).

Sections were analyzed using a Nikon microscope (Eclipse 80i) and images were processed with iPhoto (Apple Inc.) software. Transplanted dopaminergic neurons contain dark brown neuromelanin granules and can be easily distinguished from other cells in the striatum that do not contain the pigment.

\section{Thioflavin-S staining}

After mounting and drying on gelatin-coated glass slides, sections were treated with a mixture of chloroform and ethanol $(1: 1)$ for $2 \mathrm{~h}$, hydrated through the 6-grade gradient of ethanol to distilled water, and incubated for $10 \mathrm{~min}$ in $0.1 \%$ thioflavin-S (Sigma) in the dark. The slides were kept in $80 \%$ ethanol for
10-12 s, rinsed with distilled water and mounted in PVA DABCO medium.

\section{RESULTS}

Long-term survival and morphological integration of grafted dopaminergic neurons

Surviving dopaminergic neurons were observed in the grafts in both patients. However, the grafts in Patient 1 (Fig. 1c) were smaller in volume and contained much fewer TH-positive neurons than those in Patient 3 (Fig. 1a and b). We estimated that about 2700 dopaminergic neurons had survived in one injection tract in Patient 1. By comparison, in Patient 3 we previously estimated that each tract contained 12 100-29500 TH-immunoreactive dopaminergic neurons [7].

In Patient 3, the grafted dopaminergic neurons formed a dense $\mathrm{TH}$-immunoreactive network within the core of the implants (Fig. 1d and e) and extended fibers into the entire host striatum (Fig. 1g, h, j and k). By contrast, the graft-derived $\mathrm{TH}$ fibers were few in Patient 1 and rarely crossed the graft-host boundary (Fig. 1c, f, i and 1).

\section{Long-term morphological and phenotypic changes of grafted dopaminergic neurons}

During normal aging, dopaminergic neurons downregulate their expression of phenotypic markers such as TH [21-23]. We examined TH expression levels in grafted cells and in host dopaminergic neurons in the substantia nigra of Patients 1 and 3. In all 3 implanted striata (22-, 16- and 12-year old grafts), between $27 \%$ and $38 \%$ of the neuromelanin-containing cells exhibited no, or very weak, TH-immunoreactivity (Fig. 2a, c, d and g). The proportions of neuromelaninpigmented dopaminergic neurons in the substantia nigra pars compacta that did not exhibit clear THimmunoreactivity were $7 \%$ and $21 \%$ in Patients 1 and 3, respectively (Fig. 2b, e and g). In a 83-year old male control subject only a small fraction (2\%) of the pigmented substantia nigra neurons lacked TH immunoreactivity (Fig. 2f and g).

We also explored whether the levels of DAT were changed in the grafted dopaminergic neurons. Most of the DAT-positive cells in 12-22 year-old grafts exhibited very weak, 'patchy' staining (Fig. 3a-c), which contrasted with the evenly distributed staining in the substantia nigra dopaminergic neurons of the control subject (Fig. 3d). In Patient 1, some DAT-positive 

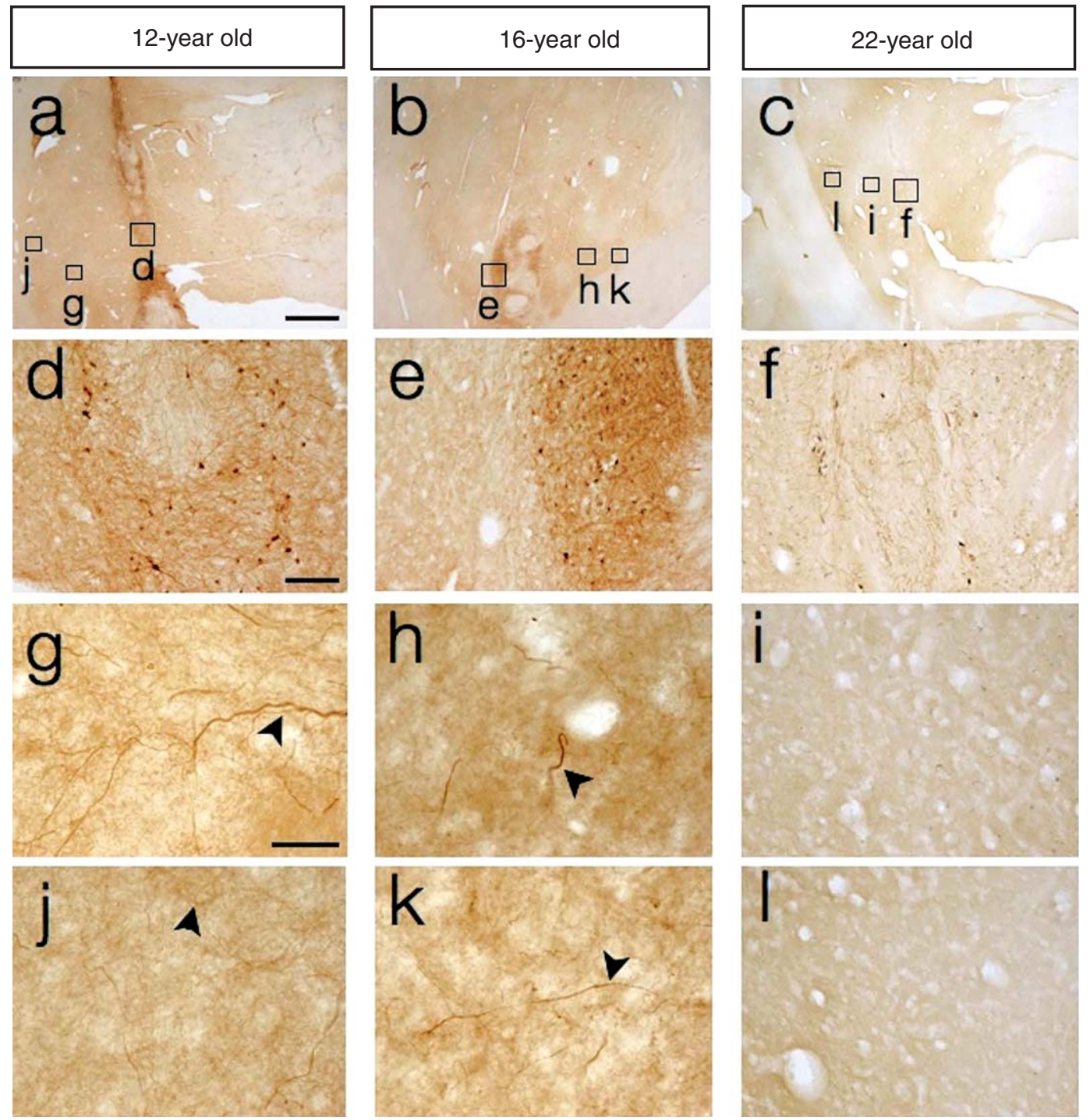

Fig. 1. Survival of grafted dopaminergic neurons and fiber extension into of the host putamen by 12-22-year old grafts. The left panel shows the 12-year old grafts with good cell survival $(\mathrm{a}, \mathrm{d})$ and extensive fiber extension into the host brain (g, j). The middle panel shows the 16-year old graft with similar degree of cell survival and fiber integration to the 12 -year old one (b, e, $h$ and $\mathrm{k}$ ). The right panel shows very poor cell survival $(\mathrm{c}, \mathrm{f})$ and fiber extension $(\mathrm{i}, 1)$ of 22-year old dopaminergic neurons in the graft. Scale bars: $2 \mathrm{~mm}(\mathrm{a}-\mathrm{c}), 100 \mu \mathrm{m}(\mathrm{d}-\mathrm{f})$ and $50 \mu \mathrm{m}(\mathrm{g}-1)$.

(Fig. 3) and TH-positive cells had an atrophic morphology with few processes. In addition, in Patient 1 the Girk2-, or calbindin-immunoreactive, pigmented neurons appeared atrophic (data not shown).

In summary, the phenotypic and morphological changes in the grafts suggest that part of the dopaminergic cells surviving long-term in these patients were dysfunctional, which might have contributed to attenuation of functional improvement over time after transplantation.

\section{Accumulation of $\alpha$-synuclein and Lewy bodies in grafted dopaminergic neurons}

We previously reported that in Patient 3, 40\% of 12 year old and $80 \%$ of 16-year old grafted, TH-positive neurons displayed diffuse $\alpha$-synuclein immunoreactivity in the cell bodies [8]. Here we found that $50 \%$ of the transplanted neuromelanin-positive neurons in Patient 1 contained detectable amounts of $\alpha$-synuclein (both homogeneous and punctate, pre- 

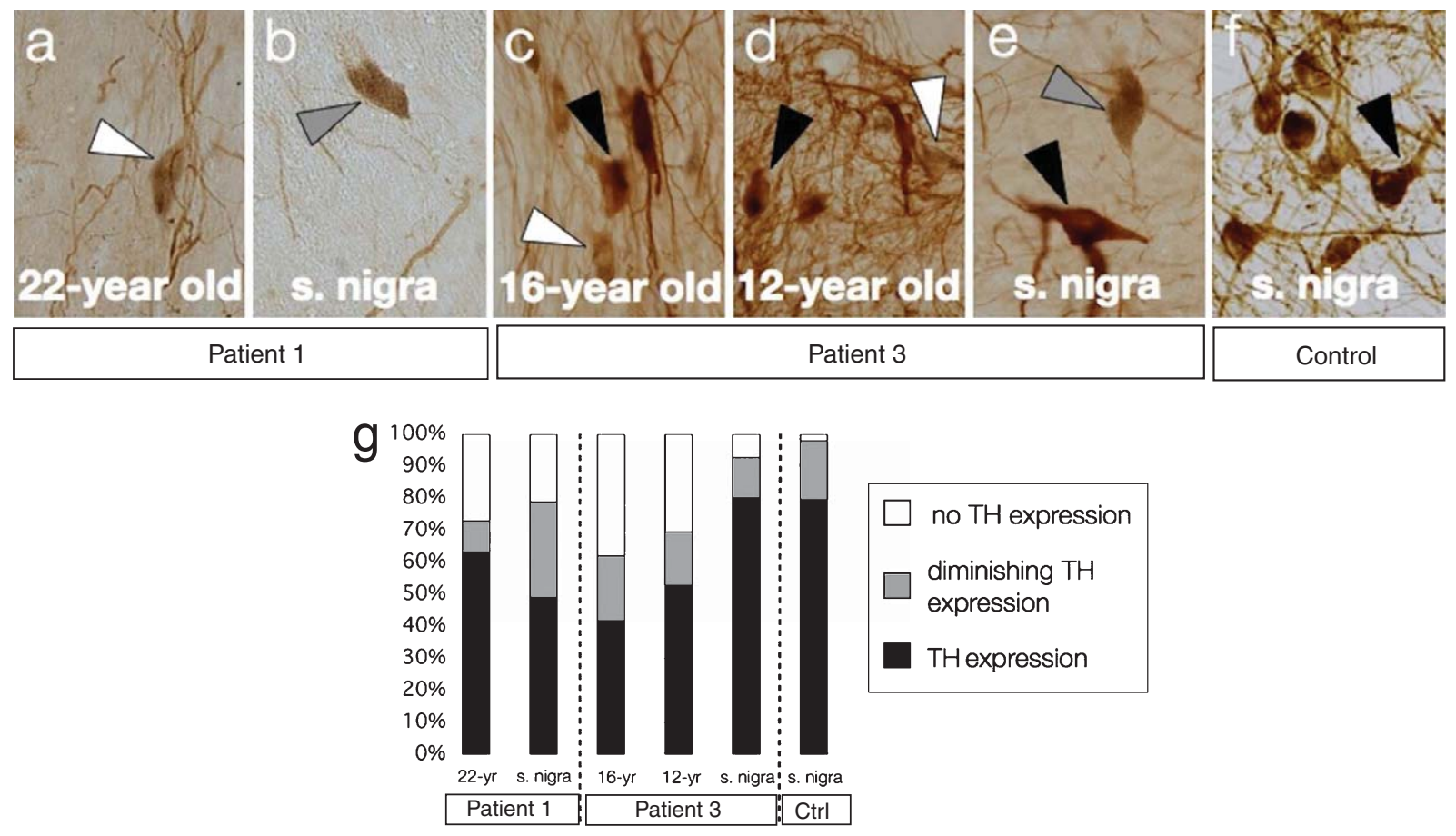

Fig. 2. Alterations in morphology and TH expression in 12-22-year old grafts. A-F exemplify representative TH-positive/neuromelanin-granule containing cells seen in examined tissues of Patient 1 (a - 22-year old graft, b - substantia nigra), Patient 3 (c - 16-year old graft, d - 12-year old graft, e - substantia nigra) and the healthy control subject (f - substantia nigra). Colors of arrows correspond to different morphological characteristics of grafted cells, quantified in $\mathrm{g}$. The chart $(\mathrm{g})$ shows the proportions of three morphologically characterized neurons

sumably reflecting soluble and insoluble forms of $\alpha$-synuclein). Moreover, at 22 years post-grafting $1.2 \%$ of neuromelanin-containing grafted cells manifested $\alpha$-synuclein-positive LBs and Lewy neurites (Fig. 4a-c). In Patient 3, we previously reported that $2 \%$ of 12 -year old and $5 \%$ of 16-year old grafted, neuromelanin-positive cells contained Lewy bodies immunoreactive for $\alpha$-synuclein [8]. As previously reported for Patient 3 [8], the LBs and Lewy neurites in Patient 1 also stained for thioflavin-S (Fig. 5) and S129phosphorylated $\alpha$-synuclein (Fig. 6). The morphology of the LBs in the grafted striatum appeared similar to those in the patient's substantia nigra (Fig. 5a-d; Fig. 6a and b). Phosphorylated $\alpha$-synuclein-positive LBs and Lewy neurites were also present in the striatum surrounding the graft and in the contralateral striatum (Fig. 6c and d).

\section{Astrogliosis in long-term mesencephalic grafts}

We observed clear GFAP-immunoreactive astrogliosis in both the 12- and the 16-year old grafts in Patient 3 (Fig. 7a, b, g and c, d, h). Dense GFAPpositive profiles enclosed surviving dopaminergic neurons, in contrast to host striatum where astrocytes were sparse in number (Fig. $7 \mathrm{~g}$ and $\mathrm{h}$ ). We observed no clear accumulation of GFAP-positive astrocytes in or around the grafts at 22-years post-operatively in Patient 1 (Fig. 7e, f and i). In addition, there were very few IBA1-positive microglial cells in and around the graft. Their morphology suggested lack of microglial activation (data not shown).

\section{DISCUSSION}

We show here that grafted fetal dopaminergic neurons can survive for more than two decades in the striatum of a PD patient who lived for 22 years following transplantation. We also find, in this and another PD patient, that long-term after transplantation, a portion of grafted neurons exhibit an abnormal phenotype suggesting that the cells have lost some of their dopaminergic features and are undergoing degenerative changes. Also, a fraction of them contain LBs, i.e., the neuropathological hallmark of PD.

Our findings support the notion that the magnitude of motor improvement following neural transplanta- 

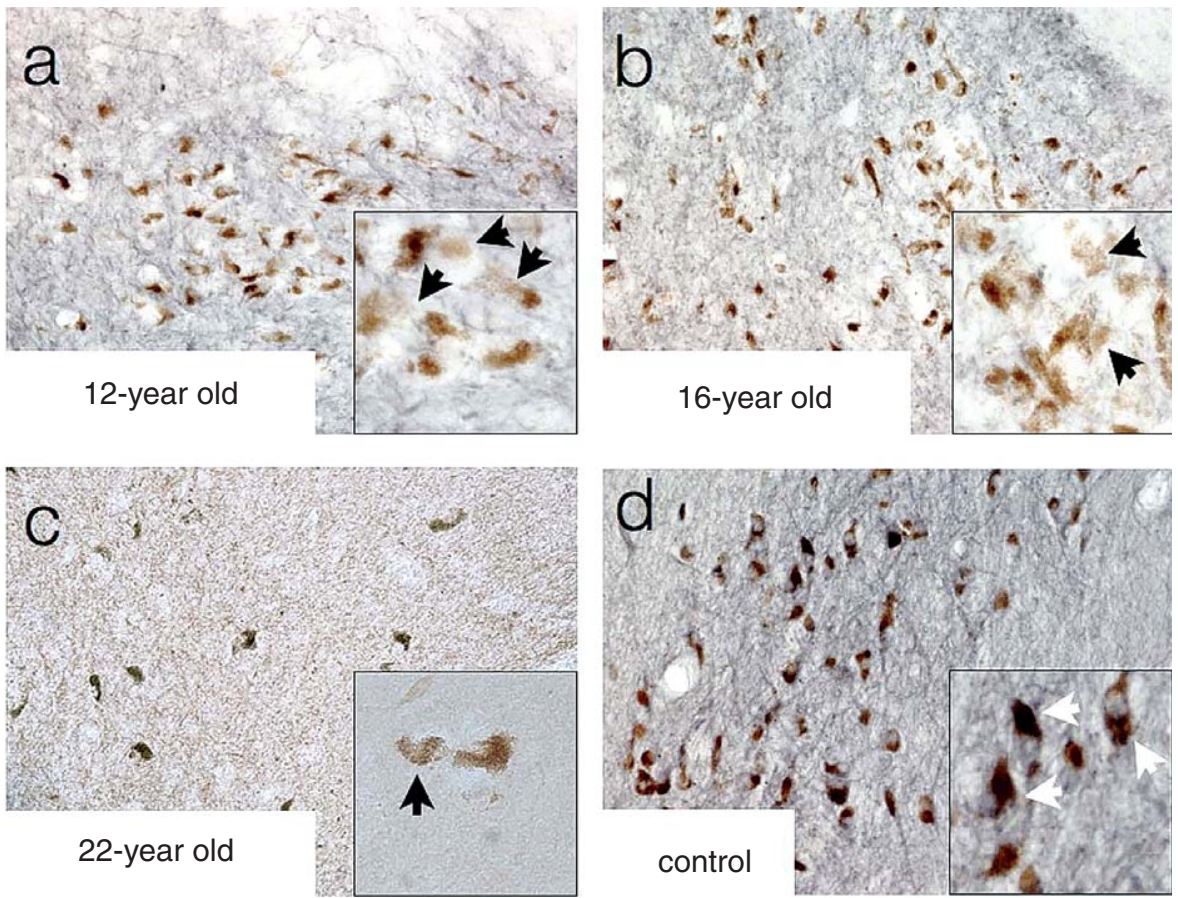

Fig. 3. Down-regulation of DAT in 12-22-year old grafts. Most of the studied cells in the 12-, and 16-year old grafts of Patient 3 (a, b) and 22-year old grafts of Patient 1 (c) displayed diminished DAT immunoreactivity (black arrows), compared with dopaminergic neurons in the substantia nigra of the control subject (d, white arrows).

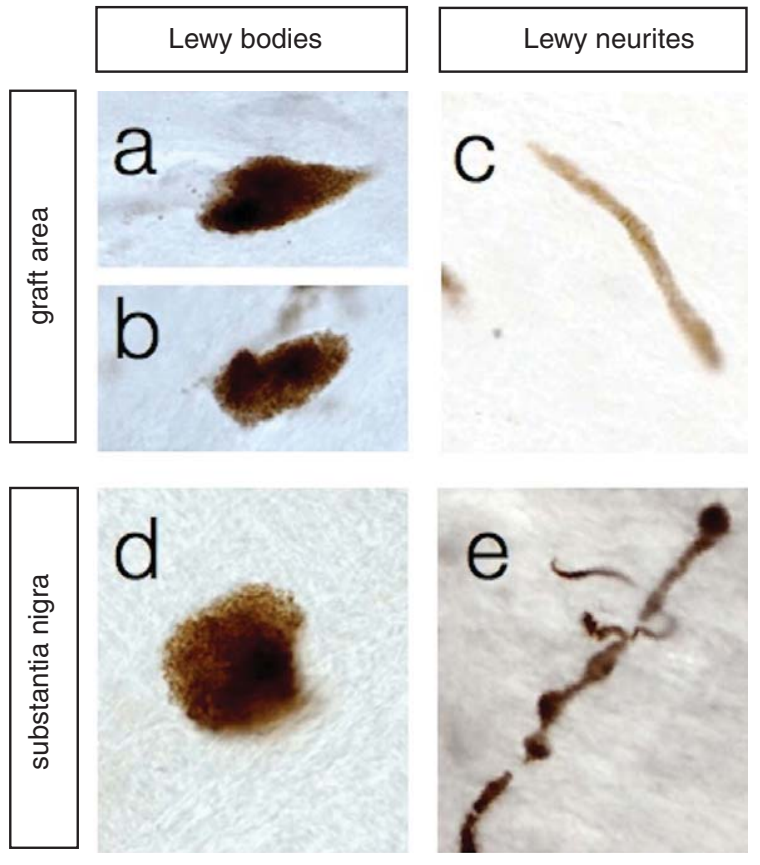

Fig. 4. Lewy bodies and Lewy neurites in 22-year old grafts. Characteristic compact, intensely $\alpha$-synuclein-immunoreactive Lewy bodies (a, b) and neurites (c) in the 22-year old graft, reminiscent of that in the substantia nigra $(\mathrm{d}, \mathrm{e})$.
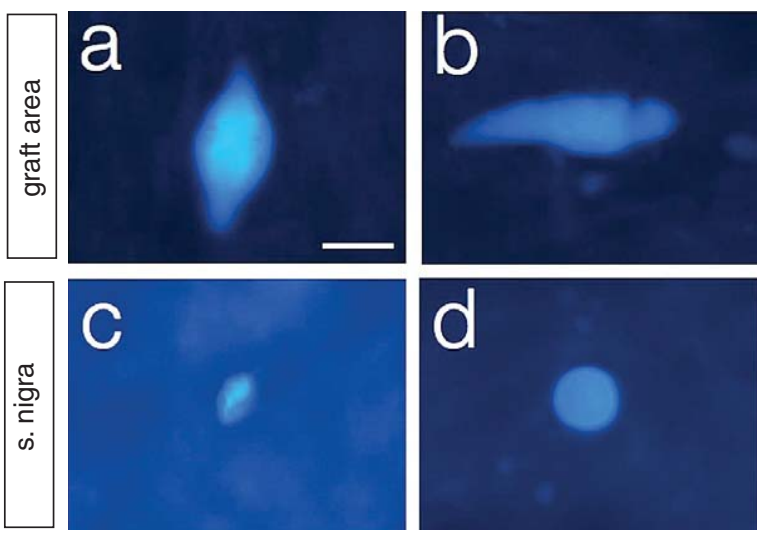

Fig. 5. Thioflavine-S positive structures in the 22-year old graft. Thioflavine-S structures were observed in Lewy bodies and Lewy neurites, both in grafted neurons (a, b) and in the host substantia nigra of Patient 1 (c, d). Scale bar $=20 \mu \mathrm{m}$.

tion in PD is dependent on the survival of the graft and its integration with the host tissue [2]. In Patient 3 , a rich and extensive dopaminergic innervation of the putamen derived from both the 12- and 16-year old grafts, demonstrated in vivo by ${ }^{18} \mathrm{~F}$-dopa PET and using histopathology at post-mortem, was consistent 


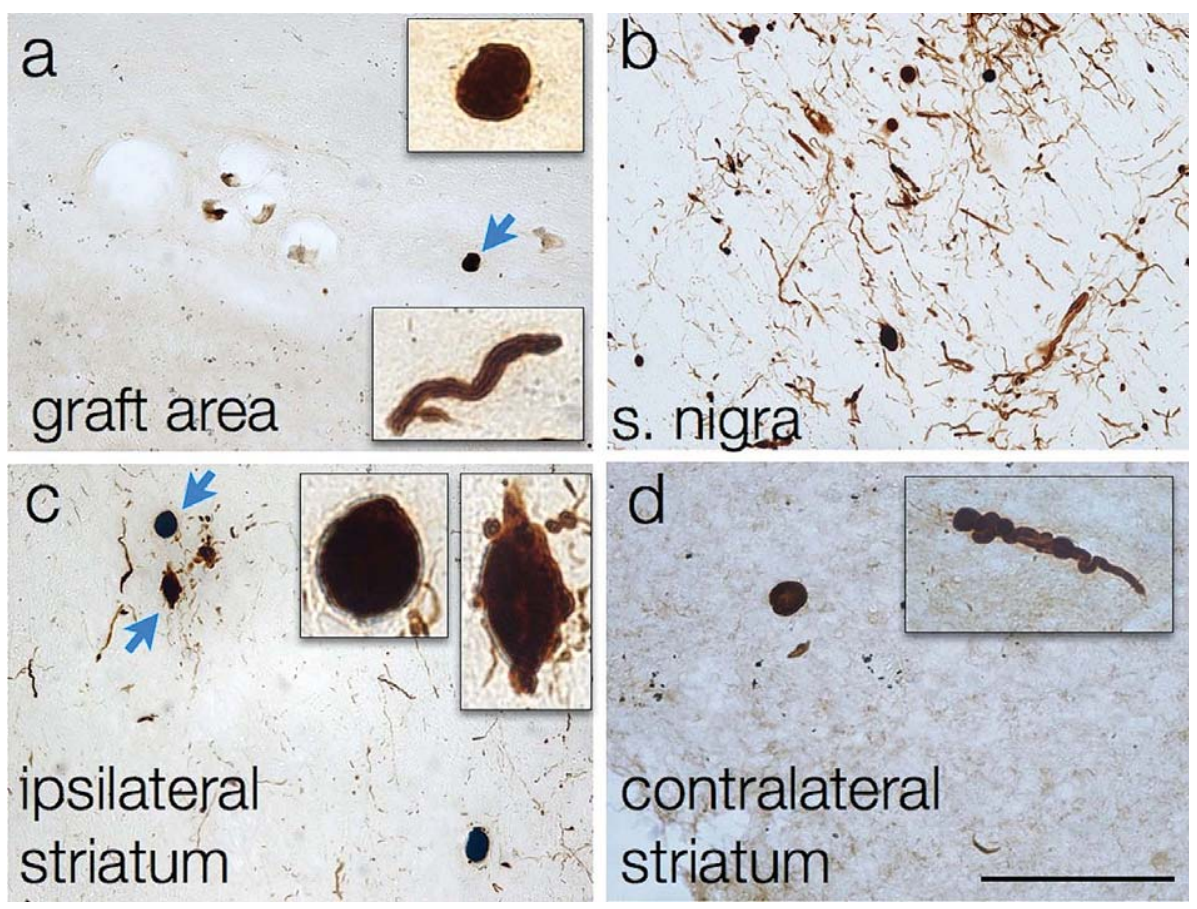

Fig. 6. Phosphorylated Ser $129 \alpha$-synuclein in the 22-year old graft. Using an antibody that binds to phosphorylated (S129) form of $\alpha$-synuclein we confirmed presence of Lewy bodies (arrows) and Lewy neurites, not only in the graft (a) and substantia nigra (b), but also in the host ipsilateral (c) (surrounding the grafts) and contralateral striatum (d). Scale bar $=100 \mu \mathrm{m}$.

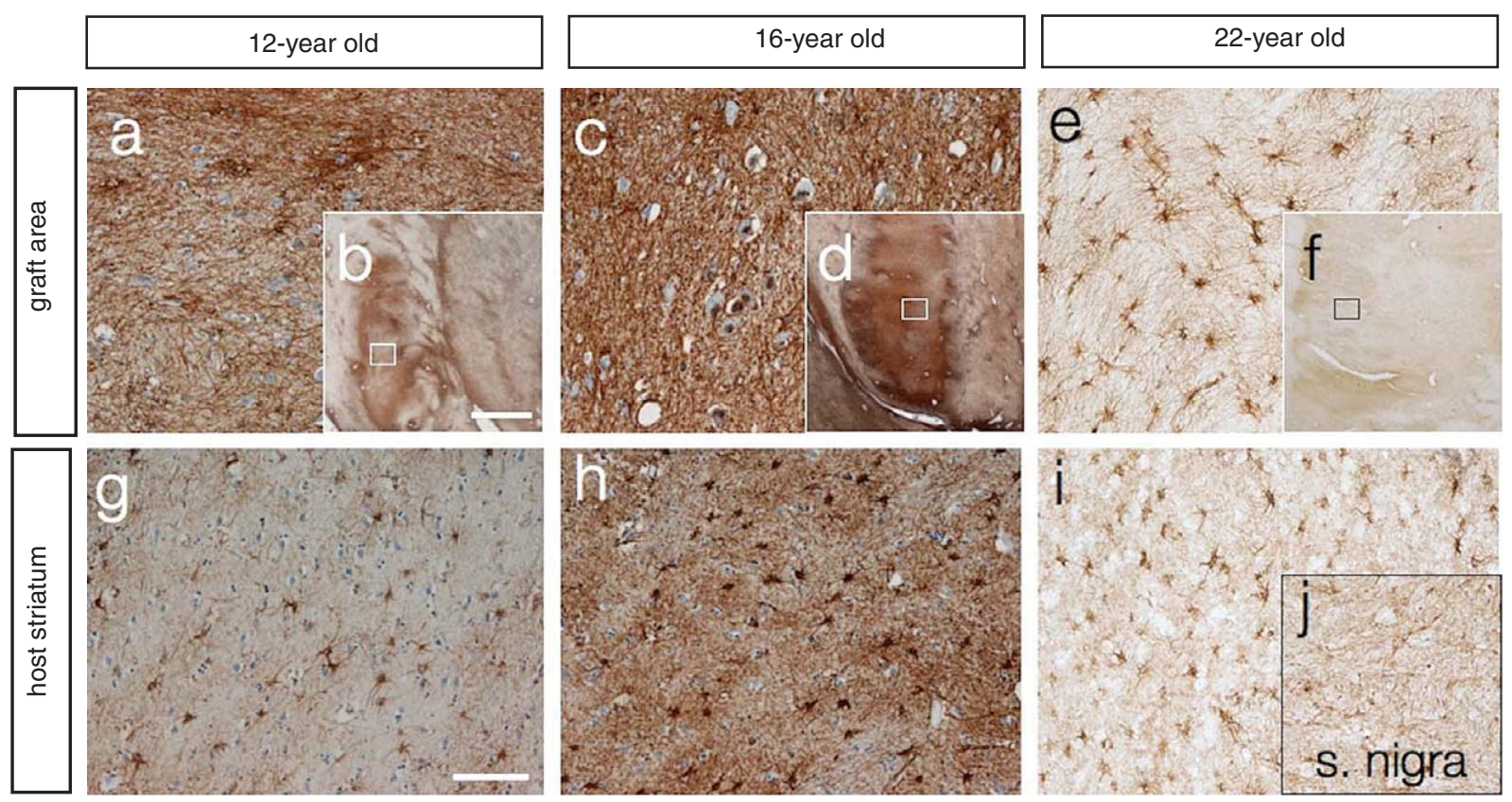

Fig. 7. Astrogliosis in 12, 16 and 22-year old grafts. Low magnified insets showed astrocyte infiltration in grafts of Patient 3 (b and d) and lack of accumulation in Patient 1 (f). Images with high magnification depict different densities of astrocytic processes in 12-16- and 22-year old grafts (Fig. a, c and e). No clear astrocytic accumulation was observed in substantia nigra of Patient 1 (j) and 3. Scale bars $2 \mathrm{~mm}$ (b, d and f) and $100 \mu \mathrm{m}(\mathrm{a}, \mathrm{c}, \mathrm{e}, \mathrm{g}, \mathrm{h}, \mathrm{i}$ and $\mathrm{j})$. 
with the positive clinical outcome $[2,16]$. Conversely, the relatively poor graft survival and virtual lack of striatal dopaminergic reinnervation in Patient 1 were in line with the lack of changes in ${ }^{18} \mathrm{~F}$-dopa uptake and modest and transient improvement of motor function [15]. The low number of surviving, grafted cells in Patient 1 was probably due to a suboptimal transplantation technique, which caused significant tissue damage at the implantation sites [15]. The ability of the grafts to integrate with the host brain circuitry might be affected by local inflammation and the presence of a "glial scar" [24]. We previously reported a host microglial reaction in association with the grafts in Patient 3 [7], and here we observed activated astrocytes locally, around the same 12- and 16-year-old grafts. By contrast, the small, poorly integrated 22-year-old transplant in Patient 1 was not surrounded by any astro- or microgliosis. This could be due to the small initial size of the surviving transplant and/or the long time that had elapsed after surgery.

One of the first events taking place in vulnerable substantia nigra neurons during the pathogenesis of PD is believed to be the loss of certain features of the dopaminergic phenotype $[21,23,25$, $26]$. In the 83-year old control subject, most of the neuromelanin-positive, presumed dopaminergic, neurons in the substantia nigra expressed $\mathrm{TH}$. One fifth (18\%) of them exhibited low levels of TH immunoreactivity and only a small fraction (2\%) was TH-negative, suggesting that most of the dopaminergic neurons in the 83 year-old control subject were still functional before death. In contrast, a high proportion of the neuromelanin-positive grafted neurons in Patients 1 and $3(27-38 \%)$ lacked key features of the dopaminergic phenotype (diminished TH and DAT expression) and also exhibited signs of atrophy, despite being relatively young, i.e. 12-22 years. These changes imply that the molecular machinery required for the production and proper recycling of dopamine was impeded in the transplanted cells 12-22 years post surgery. Thus, our data provide evidence that the functional capacity and therapeutic value of fetal tissue grafts may decline over the second decade after implantation into a PD brain, which is in line with similar findings in other grafted PD patients [4-6]. In this context, it is important to highlight that TH and $\alpha$-synuclein expression levels are negatively correlated with one another in the aging brain [22]. Thus, when $\alpha$-synuclein levels increase in the dopaminergic cell body during normal aging, the TH levels decline. A similar relationship has been suggested after a few years in fetal dopamine neurons implanted in the PD brain [4]. Interestingly, a corresponding phenomenon was observed postmortem in Huntington patients who had received fetal striatal transplants. Ten years after transplantation, a high proportion of grafts exhibited degenerative features, with dense microglial infiltration $[27,28]$. Taken together, these data indicate that fetal ventral mesencephalon or striatal tissues transplanted in Parkinsonian and Huntington patients undergo a process of degeneration in the pathological microenvironment.

It is conceivable that the loss of dopaminergic phenotype (e.g. reductions in TH and DAT) is secondary to gradual $\alpha$-synuclein accumulation. Indeed in cultured neuron-like cells, $\alpha$-synuclein has been reported to downregulate TH levels [29] and DAT activity [30, 31]. The reductions in TH levels may also be coupled to changes in activity of the dopaminergic neurons. Such homeostatic relationship between TH levels and neuronal activity was recently reported in mice [32], suggesting that high activity leads to upregulation of TH in directly affected neurons, whereas neighbouring neurons compensate by rapidly down-regulating TH levels. Hypothetically, the neuromelanin-positive and TH-negative subpopulation of grafted neurons in our patients may have undergone similar regulatory changes.

Previous studies demonstrated $\alpha$-synuclein accumulation and LB formation in grafted cells more than 10 years after transplantation [4-8]. Based on the analysis of $\alpha$-synuclein staining in two transplants (12and 16-years old) in the same host and other reports describing grafts 18 months to 4 years after surgery $[4,5]$, we postulated that $\alpha$-synuclein accumulation and LB formation progressively increase in the grafted dopaminergic neurons. However, in the present report, we observed that only $1.2 \%$ of the grafted dopaminergic neurons contained LBs, which is lower than in the 16-year old graft $(5.0 \%)$. Possibly the accuracy of our estimates is lower in Patient 1, compared to Patient 3, due to the small number of surviving dopamine neurons. Another possibility is that the LBbearing neurons eventually die, as has been suggested for dopaminergic neurons in the PD substantia nigra [33], and those that are seen at any one given time point developed LBs within the past 6 months. Notably, fetal mesencephalic grafts contain immature dopaminergic neurons both of the A9 substantia nigra and the A10 ventral tegmental area phenotype [34]. It can be postulated that the A9 subtype in the grafts is more susceptible to generate LBs and die, as is the case in the midbrain of PD patients [35-37]. Therefore, the A10 phenotype will predominate among the neurons remaining in the grafts after 22 years, and as the pool of 
grafted A9 neurons has been depleted, a lower proportion of the overall TH neuron population exhibits LBs.

In conclusion, our study shows that grafted dopaminergic neurons derived from the human ventral mesencephalon can survive over twenty years in the striatum of a parkinsonian patient. The microenvironment of the aging host parkinsonian brain, which is full of misfolded $\alpha$-synuclein, may promote aggregation formation in the grafted cells [10-14] and cause loss of dopaminergic phenotype. Our data indicate that downregulation of TH and DAT occurs in proportions of grafted neurons 12-22 years after intrastriatal transplantation, and the transplants become dysfunctional in a progressive manner, which will have a potential impact on the clinical usefulness of neural transplantation in PD.

\section{ACKNOWLEDGMENTS}

This work was supported by grants from the Swedish Research Council, Swedish Parkinson Foundation, the Nordic Center of Excellence on Neurodegeneration, the Strong Research Environment of the Swedish Research Council (NeuroFortis) and Linné grant (BAGADILICO). The study was performed within the Strategic Research Area Multipark at Lund University. The authors wish to thank B.-M. Lindberg and A. Persson for their excellent technical support.

\section{REFERENCES}

[1] Lindvall O \& Bjorklund A (2004) Cell replacement therapy: helping the brain to repair itself. NeuroRx, 1, 379-381.

[2] Hagell P \& Brundin P (2001) Cell survival and clinical outcome following intrastriatal transplantation in Parkinson disease. J Neuropathol Exp Neurol, 60, 741-752.

[3] Piccini P, Pavese N, Hagell P, Reimer J, Bjorklund A, Oertel WH, Quinn NP, Brooks DJ, \& Lindvall O (2005) Factors affecting the clinical outcome after neural transplantation in Parkinson's disease. Brain, 128, 2977-2986.

[4] Chu Y \& Kordower JH (2010) Lewy body pathology in fetal grafts. Ann N Y Acad Sci, 1184, 55-67.

[5] Kordower JH, Chu Y, Hauser RA, Freeman TB, \& Olanow CW (2008) Lewy body-like pathology in long-term embryonic nigral transplants in Parkinson's disease. Nat Med, 14, 504-506.

[6] Kordower JH, Chu Y, Hauser RA, Olanow CW, \& Freeman TB (2008) Transplanted dopaminergic neurons develop PD pathologic changes: a second case report. Mov Disord, 23, 2303-2306.

[7] Li JY, Englund E, Holton JL, Soulet D, Hagell P, Lees AJ, Lashley T, Quinn NP, Rehncrona S, Bjorklund A, Widner H, Revesz T, Lindvall O, \& Brundin P (2008) Lewy bodies in grafted neurons in subjects with Parkinson's disease suggest host-to-graft disease propagation. Nat Med, 14, 501-503.
[8] Li JY, Englund E, Widner H, Rehncrona S, Bjorklund A, Lindvall O, \& Brundin P (2010) Characterization of Lewy body pathology in 12- and 16-year-old intrastriatal mesencephalic grafts surviving in a patient with Parkinson's disease. Mov Disord, 25, 1091-1096.

[9] Obeso JA, Rodriguez-Oroz MC, Goetz CG, Marin C, Kordower JH, Rodriguez M, Hirsch EC, Farrer M, Schapira AH, \& Halliday G (2010) Missing pieces in the Parkinson's disease puzzle. Nat Med, 16, 653-661.

[10] Brundin P, Li JY, Holton JL, Lindvall O, \& Revesz T (2008) Research in motion: the enigma of Parkinson's disease pathology spread. Nat Rev Neurosci, 9, 741-745.

[11] Brundin P, Melki R, \& Kopito R (2010) Prion-like transmission of protein aggregates in neurodegenerative diseases. Nat Rev Mol Cell Biol, 11, 301-307.

[12] Frost B \& Diamond MI (2010) Prion-like mechanisms in neurodegenerative diseases. Nat Rev Neurosci, 11, 155-159.

[13] Lee SJ, Desplats P, Sigurdson C, Tsigelny I, \& Masliah E (2010) Cell-to-cell transmission of non-prion protein aggregates. Nat Rev Neurol, 6, 702-706.

[14] Olanow CW \& Prusiner SB (2009) Is Parkinson's disease a prion disorder? Proc Natl Acad Sci US A, 106, 1257112572 .

[15] Lindvall O, Rehncrona S, Brundin P, Gustavii B, Astedt B, Widner H, Lindholm T, Bjorklund A, Leenders KL, Rothwell JC, Frackowiak R, Marsden D, Johnels B, Steg G, Freedman R, Hoffer BJ, Seiger A, Bygdeman M, Stromberg I, \& Olson L (1989) Human fetal dopamine neurons grafted into the striatum in two patients with severe Parkinson's disease. A detailed account of methodology and a 6-month follow-up. Arch Neurol, 46, 615-631.

[16] Lindvall O, Brundin P, Widner H, Rehncrona S, Gustavii B, Frackowiak R, Leenders KL, Sawle G, Rothwell JC, Marsden CD, \& Björklund A (1990) Grafts of fetal dopamine neurons survive and improve motor function in Parkinson's disease. Science, 247, 574-577.

[17] Hagell P, Schrag A, Piccini P, Jahanshahi M, Brown R, Rehncrona S, Widner H, Brundin P, Rothwell JC, Odin P, Wenning GK, Morrish P, Gustavii B, Bjorklund A, Brooks DJ, Marsden CD, Quinn NP, \& Lindvall O (1999) Sequential bilateral transplantation in Parkinson's disease: effects of the second graft. Brain, 122 (Pt 6), 1121-1132.

[18] Lindvall O, Sawle G, Widner H, Rothwell JC, Bjorklund A, Brooks D, Brundin P, Frackowiak R, Marsden CD, Odin P, \& Rehncrona S (1994) Evidence for long-term survival and function of dopaminergic grafts in progressive Parkinson's disease. Ann Neurol, 35, 172-180.

[19] Lindvall O, Widner H, Rehncrona S, Brundin P, Odin P, Gustavii B, Frackowiak R, Leenders KL, Sawle G, Rothwell JC, Björklund A, \& Marsden CD (1992) Transplantation of fetal dopamine neurons in Parkinson's disease: one-year clinical and neurophysiological observations in two patients with putaminal implants. Ann Neurol, 31, 155-165.

[20] Wenning GK, Odin P, Morrish P, Rehncrona S, Widner H, Brundin P, Rothwell JC, Brown R, Gustavii B, Hagell P, Jahanshahi M, Sawle G, Bjorklund A, Brooks DJ, Marsden CD, Quinn NP, \& Lindvall O (1997) Short- and long-term survival and function of unilateral intrastriatal dopaminergic grafts in Parkinson's disease. Ann Neurol, 42, 95-107.

[21] Chu Y, Kompoliti K, Cochran EJ, Mufson EJ, \& Kordower JH (2002) Age-related decreases in Nurr1 immunoreactivity in the human substantia nigra. J Comp Neurol, 450, 203214.

[22] Chu Y \& Kordower JH (2007) Age-associated increases of alpha-synuclein in monkeys and humans are associated 
with nigrostriatal dopamine depletion: Is this the target for Parkinson's disease? Neurobiol Dis, 25, 134-149.

[23] Kastner A, Hirsch EC, Herrero MT, Javoy-Agid F, \& Agid Y (1993) Immunocytochemical quantification of tyrosine hydroxylase at a cellular level in the mesencephalon of control subjects and patients with Parkinson's and Alzheimer's disease. J Neurochem, 61, 1024-1034.

[24] Sofroniew MV (2009) Molecular dissection of reactive astrogliosis and glial scar formation. Trends Neurosci, 32, 638-647.

[25] Fearnley JM \& Lees AJ (1991) Ageing and Parkinson's disease: substantia nigra regional selectivity. Brain, 114 (Pt 5), 2283-2301.

[26] Ross GW, Petrovitch H, Abbott RD, Nelson J, Markesbery W, Davis D, Hardman J, Launer L, Masaki K, Tanner CM \& White LR (2004) Parkinsonian signs and substantia nigra neuron density in decendents elders without PD. Ann Neurol, 56, 532-539.

[27] Cicchetti F, Saporta S, Hauser RA, Parent M, Saint-Pierre M, Sanberg PR, Li XJ, Parker JR, Chu Y, Mufson EJ, Kordower JH, \& Freeman TB (2009) Neural transplants in patients with Huntington's disease undergo disease-like neuronal degeneration. Proc Natl Acad Sci U S A, 106, 12483-12488.

[28] Cicchetti F, Soulet D, \& Freeman TB (2011) Neuronal degeneration in striatal transplants and Huntington's disease: potential mechanisms and clinical implications. Brain, 134, 641-652.

[29] Yu S, Zuo X, Li Y, Zhang C, Zhou M, Zhang YA, Ueda K, \& Chan P (2004) Inhibition of tyrosine hydroxylase expression in alpha-synuclein-transfected dopaminergic neuronal cells. Neurosci Lett, 367, 34-39.

[30] Kovacs GG, Milenkovic IJ, Preusser M, \& Budka H (2008) Nigral burden of alpha-synuclein correlates with striatal dopamine deficit. Mov Disord, 23, 1608-1612.
[31] Sidhu A, Wersinger C, \& Vernier P (2004) alpha-Synuclein regulation of the dopaminergic transporter: a possible role in the pathogenesis of Parkinson's disease. FEBS Lett, 565, 1-5.

[32] Aumann TD, Egan K, Lim J, Boon WC, Bye CR, Chua HK, Baban N, Parish CL, Bobrovskaya L, Dickson P, \& Horne MK (2011) Neuronal activity regulates expression of tyrosine hydroxylase in adult mouse substantia nigra pars compacta neurons. J Neurochem, 116, 646-658.

[33] Greffard S, Verny M, Bonnet AM, Seilhean D, Hauw JJ, \& Duyckaerts C (2010) A stable proportion of Lewy body bearing neurons in the substantia nigra suggests a model in which the Lewy body causes neuronal death. Neurobiol Aging, 31 , 99-103.

[34] Thompson L, Barraud P, Andersson E, Kirik D, \& Bjorklund A (2005) Identification of dopaminergic neurons of nigral and ventral tegmental area subtypes in grafts of fetal ventral mesencephalon based on cell morphology, protein expression, and efferent projections. J Neurosci, 25, 6467-6477.

[35] Damier P, Hirsch EC, Agid Y, \& Graybiel AM (1999) The substantia nigra of the human brain. II. Patterns of loss of dopamine-containing neurons in Parkinson's disease. Brain, 122 (Pt 8), 1437-1448.

[36] German DC, Manaye KF, Sonsalla PK, \& Brooks BA (1992) Midbrain dopaminergic cell loss in Parkinson's disease and MPTP-induced parkinsonism: sparing of calbindin-D28 kcontaining cells. Ann N Y Acad Sci, 648, 42-62.

[37] Halliday GM, Ophof A, Broe M, Jensen PH, Kettle E, Fedorow H, Cartwright MI, Griffiths FM, Shepherd CE, \& Double KL (2005) Alpha-synuclein redistributes to neuromelanin lipid in the substantia nigra early in Parkinson's disease. Brain, 128, 2654-2664. 